\title{
ЗЕМЛЕПОЛЬЗОВАНИЕ ШКОТОВСКОГО РАЙОНА (ПРИМОРСКИЙ КРАЙ)
}

\author{
Маслова М. Н. \\ Тихоокеанский институт географии ДВО РАН, Владивосток \\ Дальневосточный федеральный университет, Владивосток \\ maslova.marina.99@mail.ru
}

\begin{abstract}
Аннотация. В данной статье рассмотрены типы землепользования Шкотовского района. На основе материалов, полученных при картографировании структуры использования земель, изучении нормативной документации и статистических данных, представленных на официальном сайте администрации Шкотовского района, проведен анализ структуры использования земель района. В качестве основного источника информации для картографирования были использованы космические снимки спутника Sentinel-2A, оснащенного оптико-электронным мультиспектральным сенсором (MultiSpectral Instrument - MSI). Для составления карты землепользования Шкотовского района использовался программный пакет ArcMap 10.5. В ходе выполнения работы была составлена карта типов земель по состоянию на 2017 г., картографирование выполнено в масштабе 1:100000. Заключительной частью работы являлось сравнение официального статистического материала и данных, полученных в результате картографо-статистического анализа геоинформационных данных. На основе данного материала были выявлены некоторые несоответствия официальных статистических и картографических данных. Так, например, не совпадает показатель доли лесных территорий: при картографировании было выявлено меньше территорий, занятых лесами, чем указано в официальной статистической информации. Не совпадают также данные о сельскохозяйственных землях и территорий населенных пунктов. Автором предложены возможные причины данных расхождений. В целом, по результатам картографирования, в структуре использования земель Шкотовского района преобладают леса, площадь которых составляет 1957,75 км². Лесные земли сосредоточены в южной, восточной и особенно в северной части района. Луга приурочены к населенным пунктам. Их площадь составляет 131,16 км². К долинам рек и временным водотокам на склонах возвышенностей приурочены редколесья. Площадь данного типа земель составляет 410,12 км². Значительно меньшую площадь за-

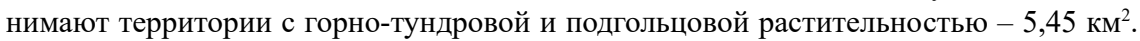
Сельскохозяйственные земли занимают площадь 81,55 км². Приурочены они к долинам рек и расположенным рядом с ними населенными пунктами. Населенные пункты занимают территорию, равную 53,8 км².
\end{abstract}

Ключевые слова: использование земель, типы земель, картографирование, картографический анализ, Шкотовский район. 


\title{
LAND USE OF SHKOTOVSKY DISTRICT (PRIMORYE KRAY)
}

\author{
Maslova M.N. \\ Pacific Geographical Institute FEB RAS, Vladivostok \\ Far Eastern Federal University, Vladivostok
}

Annotation. Types of land use of Shkotovsky distict as one of the specific districts of Primorye by physical-geographical features are reviewed in this article. The material for districts's lands structure was collected by basing on the mapping of a structure of land use, studying of a statistic material, which is given on the official website of the administration of Shkotovsky district and normative documentation of the administration of Shkotovsky district. The space photos made by Sentinel-2A are used in this work as the main source of information for cartographic analysis. The satellite is equipped with optical-electronic multi spectral sensor - MSI. ArcMap 10.5 programme was used for creating of the map of the land use of Shkotovsky district. The main result of the work is the map of the types of lands, created for 2017 year. The cartographic analysis was made with scale 1:100000. In the final part of the work the comparing of the official statistic material and data, which were gotten as a result of the cartographic analysis, has been made. As a result, some mismatches of the data were found. So, the indicator of the share of forest territories does not coincide. The cartographic analysis showed that there were less forests area than it can be seen in statistics. The data on agricultural lands and territories of settlements also do not coincide. Some possible sircumstances of mismatches were offered by the author. In general, according to the results of mapping, forests prevail in the structure of land use in the Shkotovsky district, the area of which is $1957.75 \mathrm{~km}^{2}$. Another type of land is confined to settlements - meadows. Their area is $131.16 \mathrm{~km}^{2}$. The area of woodlands is $410.12 \mathrm{~km}^{2}$. A much smaller area is occupied by territories with mountain-tundra and subalpine vegetation $-5.45 \mathrm{~km}^{2}$. Agricultural land covers an area of $81.55 \mathrm{~km}^{2} .53 .8 \mathrm{~km}^{2}$ of the territory of the Shkotovsky district are occupied by settlements. trict.

Key words: land use, land use types, mapping, cartographic analysis, Shkotovsky dis-

Шкотовский муниципальный район находится в южной части Приморского края и состоит из двух территорий - северной и южной. Административный центр района находится в пгт. Смоляниново. Общая протяженность границы Шкотовского муниципального района составляет 334,9 км, из них 286,7 км - сухопутная часть и 48,2 км водная часть границы [3]. Общая площадь - 2664,5 км², что составляет около 1,5\% от территории Приморского края.

Район окружён с трёх сторон хребтами: на севере - горами Пржевальского (гора Лысая, 1241 м), на востоке - хребтом Большой Воробей (гора Туманная, 1229 м), на юге - Ливадийским хребтом (гора 
Ливадийская (Пидан), 1332 м) [12]. Территория, занимаемая Шкотовским районом, находится в восточной части Амурской плиты. Максимальный возраст отложений на территории района - поздняя пермь (260 млн. лет) на левобережье реки Артёмовки и между реками Шкотовка и Стеклянуха.

По А. М. Короткому [2] на территории Шкотовского района выделяется ряд морфологических элементов рельефа. На юге расположен участок среднегорного расчлененного рельефа - ступенчато-расчлененное среднегорье. На севере района выделяется участок плоскогорного среднегорья и низкогорья. Значительную восточную часть района занимает низкогорный рельеф. Центральную часть Шкотовского района занимает мелкогорный и холмисто-увалистый рельеф, образующий придолинный уровень в среднем течении большинства крупных рек и поверхности водоразделов в их нижнем течении. В западной части района выделяется высокая аккумулятивно-денудационная равнина. В обрамлении побережья Японского моря формируется низкая аккумулятивная озерно-аллювиальная равнина. Аккумулятивный рельеф представлен преимущественно разновозрастными террасированными уровнями в речных долинах и в зоне морского побережья [12].

По классификации Б. П. Алисова Шкотовский район, как и Приморский край, относится к муссонной области умеренного пояса [1]. Атмосферная циркуляция является одним из главных климатообразующих факторов. Здесь характерна сезонная смена воздушных течений, возникающих под влиянием термических контрастов между материком и океаном. В течение всей зимы район находится под влиянием восточной периферии зимнего азиатского антициклона. В целом зима в Шкотовском районе мягкая, малоснежная, с частыми оттепелями, господствует сухой и холодный континентальный воздух, погода ясная морозная с преобладанием северных и северо-западных ветров. Лето теплое, влажное, с частыми туманами. Во второй половине начинаются затяжные дожди, приводящие к наводнениям. Муссоны, дующие с моря, приносят большое количество осадков [10].

По территории района протекают реки Артемовка (73 км), Шкотовка (59 км), Суходол (49,7 км), Петровка (45 км), берущие начало в отрогах Сихотэ-Алиня и впадающие в Уссурийский залив. Все реки и ручьи имеют горный характер, питание рек смешанное.

Согласно почвенно-географическому районированию Дальнего Востока Б.Ф. Пшеничникова, юго-западная часть территории Шко- 
товского района относится к Уссурийско-Ханкайской провинции умеренных промерзающих почв, основная часть территории района принадлежит Южно-Сихотэ-Алинской горной провинции. Провинции относятся к зоне бурых и подзолисто-бурых лесных почв хвойно-широколиственных и широколиственных лесов Восточной буроземно-лесной области Суббореального пояса [8]. В пределах Южно-Сихотэ-Алинской горной провинции со среднегорным рельефом выделяются горно-бурые почвы и подзолистые иллювиально-гумусовые почвы [2].

Согласно схеме геоботанического районирования Б. П. Колесникова, на территории Шкотовского района выделяются две геоботанические области. Первая - Южно-Охотская область темнохвойных лесов, округ южного Сихотэ-Алиня. Вторая область - Восточно-Азиатская хвойно-широколиственных лесов, Сучанско-Владивостокский горно-приморский округ лиановых кедровников и чернопихтарников [5].

По физико-географическому районированию Ю. П. Пармузина [10] Шкотовский район принадлежит Сихотэ-Алинской горной области Южно-Сихотэ-Алинской провинции. Орография территории определяется отходящими от главного водораздельного гребня к югу высокими отрогами, постепенно снижающимися своими окончаниями в виде скалистых мысов, далеко вдающихся в водную поверхность залива.

Основная часть земельного фонда Шкотовского района покрыта лесными массивами. Площади пригодных для хозяйственного использования земель ограничены и расположены в основном в долинах рек и вдоль транспортных артерий района. Лесные массивы Шкотовского района располагают значительным потенциалом для заготовки пищевого, технического и лекарственного сырья. Недра района богаты различными полезными ископаемыми, строительными материалами, минеральными, минерализованными и экологически чистыми водами. Экономику района образуют производство и распределение электроэнергии, газа и воды, обрабатывающие производства, рыболовство и марикультура, сельское хозяйство, строительство. Шкотовский район имеет огромный рекреационный потенциал и является одним из перспективных в крае для развития туризма [11].

В настоящее время большое внимание уделяется развитию Дальнего Востока, в особенности Приморского края, составными частя- 
ми которого являются муниципальные районы и городские округа. С этим связана актуальность изучения типов землепользования с целью их активного использования для развития экономики района и Приморского края в целом. Модельным участком для анализа структуры использования земель выступал Шкотовский район.

Основным теоретическим понятием данной работы является понятие «природопользование». По определению А. Шейнгауза - это практическая деятельность, связанная либо с непосредственным использованием природных ресурсов и условий территориальных комплексов, либо с воздействием на них, которое заключается не только в вовлечении этих ресурсов и условий в экономически эффективное производство, но и предусматривает их восстановление и преобразование. Изучение структуры использования земель является одним из ключевых подходов в оценке системы природопользования территории. Земельные ресурсы - это совокупность участков территории земной поверхности, обладающих конкретными природными условиями, природно-ресурсными свойствами, определяющими возможности их включения в производственную деятельность человека [9].

В данной работе оценка системы использования земель была осуществлена с помощью геоинформационных систем. В настоящее время ГИС стала одним из основных инструментов моделирования природных, хозяйственных, социальных процессов и ситуаций, прослеживания их связей, взаимодействий, прогнозирования развития в пространстве и времени и отображения их в соответствующих слоях на языке электронных карт, получения новой качественной и количественной информации, а главное - средством обеспечения принятия решений управленческого характера и представления выводов [7].

При создании карты использования земель использовался программный пакет ArcMap 10.5. Для изучения структуры использования земель Шкотовского района были использованы снимки спутника Sentinel-2A [6].

Общая площадь Шкотовского района Приморского края - 2664,5 км² $^{2} 266,5$ тыс. га). Площадь застроенных земель составляет 16,5 тыс. га, из которых 89,1 \% заняты хозяйственными объектами, 10,9 \% жилой застройкой.

Согласно рассчитанным данным, полученным при составлении карты типов земель Шкотовского района, общая площадь района составляет 2656,97 км². Из анализа была исключена площадь, занятая 
озерами, которые занимают 17,14 км². Анализируемая площадь земель составляет 2639,83 км².

По результатам картографирования структуры использования земель установлено, что большую часть территории Шкотовского района, а это 74,2 \% всех земель района, занимают леса. Совокупная площадь лесов составляет 1957,75 км². Лесные земли сосредоточены в южной, восточной и особенно в северной части района, в долинах рек и на возвышенностях.

Согласно данным Стратегии развития района [11], общая площадь лесных земель района - 2309 км $^{2}$, что составляет 86,6 \% от общей площади района. Преобладают земли лесного фонда и земли особо охраняемых территорий (62,9 \% и 10,4 \% от площади Шкотовского района). Лесные насаждения, не входящие в лесной фонд, преобладают на землях сельскохозяйственного назначения и населенных пунктов.

При картографировании землепользования Шкотовского района также был выделен такой тип земель, как луга. Эти земли приурочены к населенным пунктам, а также окружают территорию сельскохозяйственных земель. Занимаемая лугами территория составляет 131,16 км$^{2}$ или около $5 \%$ от площади района. Главным образом луга сосредоточены в центральной, юго-западной и южной части района.

Еще один тип земель - редколесья, приуроченные к долинам рек и временным водотокам на склонах возвышенностей. Площадь редколесий составляет 410,12 км². Наибольшее распространение редколесья получили в южной части района в долинах рек Гамаюнова, Мелководный ключ, Суходол, руч. Бабушкин; Лобога, Смяличи и Воробьевка в центральной части; на севере района - p. Артемовка.

Очень маленькую долю по сравнению с другими типами земель занимают территории с горно-тундровой и подгольцовой растительностью. Их площадь равна 5,45 км², что составляет всего 0,2 \% от площади всех земель района. Эти земли приурочены к вершинам гор Ливадийского хребта на юге (г. Ливадийская) и хребта Большой Воробей на востоке (г. Туманная) - это области горно-тундровой и подгольцовой растительности.

Согласно статистическим данным, полученным при построении карты (рис.), тип сельскохозяйственных земель занимает площадь 81,55 км $^{2}$, что составляет 3,09 \% от всех земель района. Сельскохозяйственные земли приурочены к долинам рек и расположенным ря- 


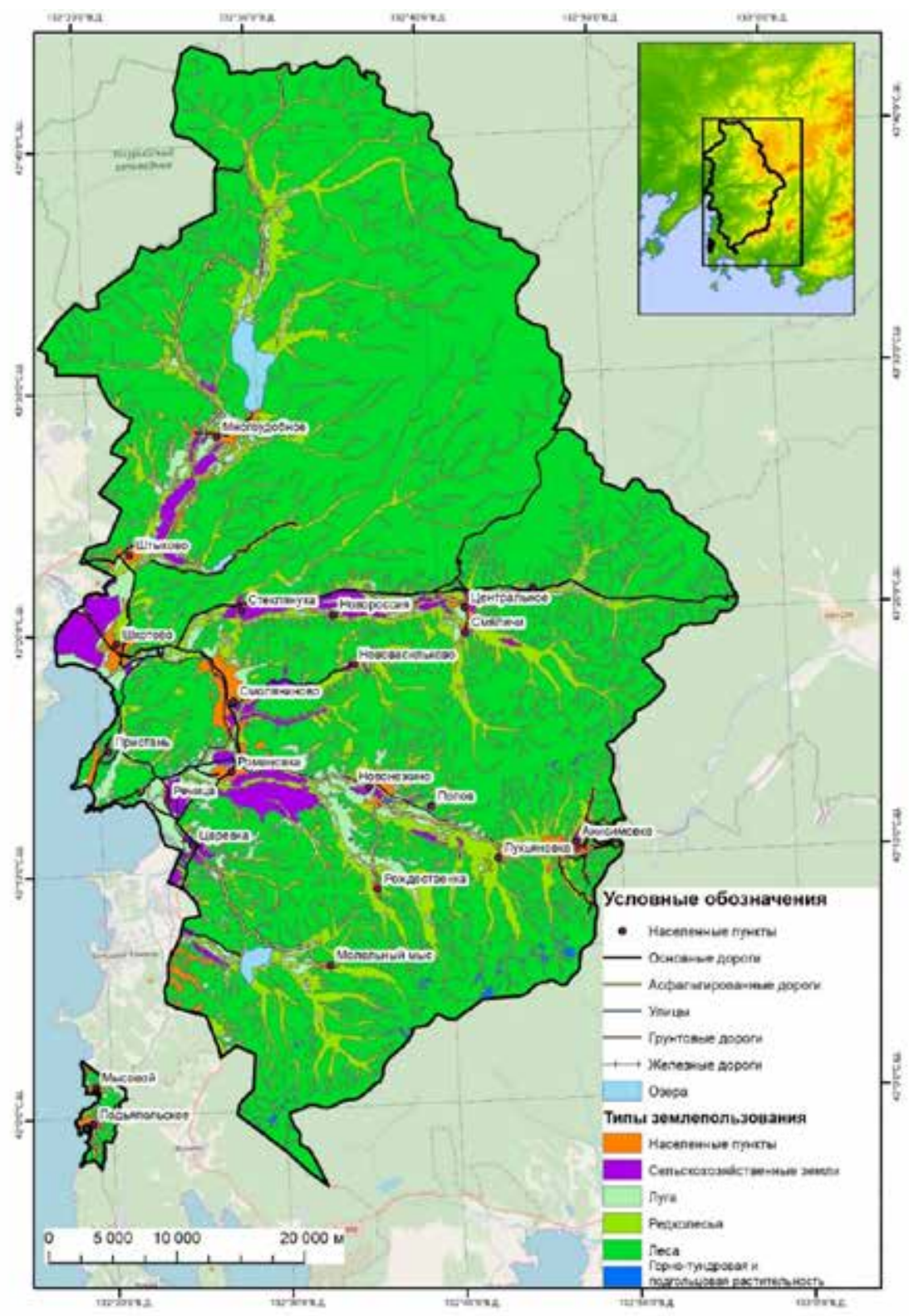

Рис. Карта использования земель Шкотовского района 
дом с ними населенными пунктам. Наибольшие площади сельскохозяйственных земель расположены близ пгт. Шкотово, с. Романовка, земли между с. Стеклянуха и с. Новороссия, между п. Штыково и с. Многоудобное. Такая концентрация этого типа земель в центральной части района определяется наличием на данных территориях сельхозпредприятий. Активно используются земли садоводческими и огородническими объединениями, личными подсобными и крестьянско-фермерскими хозяйствами.

На территории района площадь земель сельскохозяйственного назначения составляет 255,89 км². Согласно Стратегии социально-экономического развития Шкотовского муниципального района, около 155 км $^{2}$ (или $60 \%$ от общего фонда земель сельскохозяйственного назначения) предназначены для производства сельхозпродукции [11]. Площадь пашни, принадлежащей сельхозпредприятиям и организациям Шкотовского района, составляет 54,84 км² [4].

В собственности Министерства обороны в настоящее время находится 12,4 тыс. га брошенных или используемых сельскохозяйственными товаропроизводителями земель. Из них более 6 тыс. га - бывшего ФГУ СП «Романовское» и более 1 тыс. га - бывшего ФГУ СП «Многоудобненское» [4].

Общая площадь территории, занимаемой населенными пунктами, согласно полученным при картографировании данным, составляет 53,8 км². Населенные пункты приурочены к долинам рек Шкотовского района, а также к прибрежным районам Уссурийского залива (бухты Муравьиной, Суходол, Пяти Охотников, Подъяпольского).

В составе Шкотовского района выделяется 7 муниципальных образований и 21 населенный пункт. Наиболее крупными населенными пунктами являются пгт. Смоляниново (административный центр), пгт. Шкотово, с. Анисимовка.

Согласно Стратегии социально-экономического развития Шкотовского муниципального района, площадь населенных пунктов составляет 4 \% [11]. Однако, при картографировании площадь земель, занятых населенными пунктами составила немногим более $2 \%$.

Таким образом, Шкотовский район - район, обладающий большим запасом земельных ресурсов, разнообразных по своему составу. Большую часть территории района составляют земли, занятые лесом. Лесные ресурсы имеют важное природоохранное и рекреационное значение, как для самого района, так и для прилегающих террито- 
рий. При этом Шкотовский район не является лесосырьевым районом Приморского края.

Сельское хозяйство не является главной сферой экономики района, поэтому сельскохозяйственные земли занимают немногим более $3 \%$ от всей площади района. Однако администрацией Шкотовского муниципального района предоставлена информация о том, что земли сельскохозяйственного назначения составляют $10 \%$. Это объясняется тем, что многие имеющиеся земли не используются максимально. Часть из них уже заброшена и не используется совсем, часть требует проведения мелиоративных работ. В связи с этим данные земли нами классифицированы как луга.

Научный руководитель: к.г.н., профессор Зонов Ю. Б., ШЕН ДВФУ, кафедра географии и устойчивого развития геосистем.

\section{Литература}

1. Алисов Б.П. Климат СССР. М.: Изд-во МГУ, 1956. 126 с.

2. Геосистемы Дальнего Востока России на рубеже XX-XXI веков: в 3 т. / колл. авторов; под общ. ред. академика П.Я. Бакланова. Том 1. Природные геосистемы и их компоненты / колл. авторов; отв. ред. С. С. Ганзей. Владивосток: Дальнаука, 2008. $428 \mathrm{c}$.

3. Закон Приморского края от 07 декабря 2004 года N 192-КЗ О Шкотовском муниципальном районе [Электронный ресурс] // Электронный фонд правовой и нормативно-технической документации. - Режим доступа: http://docs.cntd.ru/ document/494211732 (дата обращения: 10.07.2019).

4. Земли сельскохозяйственного назначения [Электронный ресурс] // Шкотовский район. - Режим доступа: http://shkotovskiy.ru/home/agriculture/agroland (дата обращения: 10.07.2019).

5. Колесников Б. П. Растительность // Дальний Восток. Физико-географическая характеристика. М.: Изд-во АН СССР, 1961. С. 183-245.

6. Космические снимки [Электронный ресурс] // Геоаналитика. Агро. - Режим доступа: http://agro.geoanalitika.com/ru/products/kosmicheskie_snimki/ (дата обращения: 10.07.2019).

7. Лурье И. К. Геоинформационное картографирование. Методы геоинформатики и цифровой обработки космических снимков: учебник. М.: КДУ, 2008. 422 с.

8. Пшеничников Б.Ф. Основы почвоведения и географии почв. Владивосток: Изд-во ВГУЭС, 2008. 244 с.

9. Региональное природопользование: методы изучения, оценок, управления / Под ред. П.Я. Бакланова, В.П. Каракина. М.: Логос, 2002. 160 с.

10. Свинухов Г. В. Физическая география Приморского края. Владивосток: Издво ДВГУ, 1990. 208 с.

11. Стратегия социально-экономического развития Шкотовского муниципального района [Электронный ресурс] // Шкотовский район. - Режим доступа: http:// shkotovskiy.ru/home/strategy/1/3 (дата обращения: 10.07.2019). 
12. Шкотовский район: к 140-летию пос. Шкотово и 80 -летию образования района / сост. Ю. И. Берсенев и др.; отв. ред. П. Ф. Бровко. Владивосток: Изд-во Дальневост. ун-та, 2005. 185 с.

\section{References}

1. Alisov B.P. Klimat SSSR [Climate of the USSR]. Moscow, Moscow St. Univ. Publ., 1956. $126 \mathrm{p}$.

2. Geosistemy Dal'nego Vostoka Rossii na rubezhe XX-XXI vekov: $v 3 t$. [Geosystems of the Far East of Russia at the turn of the XX-XXI centuries: in 3 volumes/ Ed. P.Ya. Baklanov]. Tom 1. Prirodnye geosistemy i ih komponenty / koll. avtorov; otv. red. S.S. Ganzei [Volume 1. Natural geosystems and their components / a team of authors; resp. ed. S. S. Ganzey]. Vladivostok: Dalnauka Publ., 2008. 428 p.

3. Zakon Primorskogo kraya ot 07 dekabrya 2004 goda N 192-KZ O SHkotovskom municipal'nom rajone [The Law of the Primorsky Territory of December 7, 2004 No.192-KZ about the Shkotovsky Municipal District]. Available at: http://docs.cntd.ru/ document/494211732 (accessed 10.07.2019).

4. Zemli sel'skohozyajstvennogo naznacheniya [Agricultural land of Shkotovsky district]. Available at: http://shkotovskiy.ru/home/agriculture/agroland (accessed 10.07.2019).

5. Kolesnikov B.P. [Vegetation]. Dal'nij Vostok. Fiziko-geograficheskaya harakteristika [Far East. Physical-geographical characteristics]. Moscow, AN SSSR Publ., 1961, pp. 183-245.

6. Kosmicheskie snimki [Space images]. Available at: http://agro.geoanalitika.com/ru/ products/kosmicheskie_snimki/(accessed 10.07.2019)

7. Lurie I.K. Geoinformacionnoe kartografirovanie. Metody geoinformatiki i cifrovoj obrabotki kosmicheskih snimkov [Geoinformation mapping. Methods of geoinformatics and digital processing of satellite images]. Moscow, KDU Publ., 2008. 422 p.

8. Pshenichnikov B.F. Osnovy pochvovedeniya i geografii pochv [Fundamentals of soil science and soil geography]. Vladivostok: VGUES Publ., 2008. 244 p.

9. Regional'noe prirodopol'zovanie: metody izucheniya, ocenok, upravleniya [Regional environmental management: methods of study, evaluation, management] / Eds. Baklanov P. Ya., Karakin V.P. Moscow, Logos Publ., 2002. 160 p.

10. Svinukhov G.V. Fizicheskaya geografiya Primorskogo kraya [Physical geography of Primorsky Krai]. Vladivostok, DVGU Publ., 1990. 208 p.

11. Strategiya social'no-ekonomicheskogo razvitiya Shkotovskogo municipal'nogo rajon [Strategy of social and economic development of the Shkotovsky municipal district] Available at: http://shkotovskiy.ru/home/strategy/1/3 (accessed 10.07.2019)

12. Shkotovskij rajon: $k$ 140-letiyu pos. Shkotovo $i$ 80-letiyu obrazovaniya rajona [Shkotovsky district: on the 140th anniversary of the village Shkotovo and the 80th anniversary of the formation of the district]. Ed. Brovko P. F. Vladivostok, Dalnevost. Univ. Publ., 2005. 185 p. 